\title{
O MÉTODO DESDOBRAMENTO DA FUNÇÃO QUALIDADE - QFD - NO PLANEJAMENTO DO SERVIÇO DE ENFERMAGEM*
}

\author{
Laura Misue Matsuda** \\ Yolanda Dora Martinez Évora*** \\ Flávio Souto Boan****
}

MATSUDA, L.M.; ÉVORA, Y.D.M.; BOAN, F.S. O método desdobramento da função qualidade - QFD - no planejamento do serviço de enfermagem. Rev.latino-am.enfermagem, Ribeirão Preto, v. 8, n. 5, p. 97-105, outubro 2000.

"Foco no Cliente" postura a ser adotada na obtenção de produtos de qualidade. Alicerçada na abordagem da Gestão pela Qualidade Total, o Desdobramento da Função Qualidade é a ferramenta que operacionaliza essa perspectiva. Este estudo objetivou criar uma proposta de planejamento para o Serviço de Enfermagem, seguindo as etapas e ações desta metodologia, que iniciou com o levantamento das necessidades de 106 clientes hospitalizados. Através de matrizes e diagramas, os dados foram desdobrados e priorizados perfazendo as dezessete etapas propostas. O resultado mostrou que no atendimento de enfermagem, o cliente valoriza a interação à técnica e que este método possibilita implementar a qualidade.

UNITERMOS: desdobramento, planejamento, enfermagem, qualidade

\section{INTRODUÇÃO}

Desde os nossos primeiros contatos com a enfermagem, temos vivenciado uma forma de atuação fragmentada, impessoal, empírica, ritualística e muitas vezes desumana para com o cliente. Mesmo considerando as diversas nuances que afetam estes profissionais no seu contexto social e econômico, vemos que, não obstante o avanço tecnológico e científico, a sua prática, ao longo dos anos, não tem apresentado mudanças significativas. Isto quer dizer que a lacuna entre teoria e prática, apesar das discussões, está longe de ser solucionada.

No panorama antes citado, os cuidadores não se detêm aos aspectos relacionados à humanização e parceria, sendo estes conceitos básicos inerentes à qualidade do serviço.

Sabemos que o advento da crise na saúde tem impulsionado as instituições públicas à privatização $\mathrm{e}$ estas, por sua vez, têm procurado implementar atividades racionalizadoras a fim de reduzir os custos. Para tanto, a tentativa de otimizar os processos e atender melhor os clientes já passa a ser realidade em algumas instituições de saúde em nosso país.

Acreditamos que a participação do cliente junto aos trabalhadores, conduz a um serviço mais humano e eficaz. Dessa forma, a filosofia de gerenciamento denominada Gestão pela Qualidade Total (GQT), ao nosso ver, vislumbra um caminho para a enfermagem visto que os seus conceitos e princípios se propõe a estruturar o trabalho humano. Esta abordagem, se aplicada à gestão do serviço de enfermagem, possibilita melhorar a qualidade tanto técnica como humana destes profissionais tendo como resultado a satisfação das pessoas.

CAMPOS (1992, p. 4) define a GQT como sendo "um novo modelo gerencial centrado no controle do processo, tendo como meta a satisfação das necessidades das pessoas." Esta abordagem está alicerçada em teorias científicas como as da administração, matemática, estatística bem como naquelas do comportamento humano.

\footnotetext{
* Este artigo constite no resumo da Dissertação de Mestrado de MATSUDA, L.M. O método desdobramento da função qualidade - QFD - no planejamento do serviço de enfermagem. apresentada na Escola de Enfermagem de Ribeirão Preto da Universidade de São Paulo. 1997

** Enfermeira - Doutoranda em Enfermagem Fundamental da Escola de Enfermagem de Ribeirão Preto da Universidade de São Paulo

*** Professor Doutor do Departamento de Enfermagem Geral e Especializada da Escola de Enfermagem de Ribeirão Preto da Universidade de São Paulo. Orientadora

**** Engenheiro Eletricista - Mestre em Engenharia da Produção e Consultor da Fundação de Desenvolvimento Gerencial - Belo Horizonte-MG
} 
Dentre os princípios que norteiam a GQT temos: identificar os problemas e atuar segundo as prioridades, gerenciar ao longo do processo, valorizar o cliente, prevenir problemas, respeitar os empregados, definir e executar as metas da empresa dentre outros.

Em nosso ver a abordagem da Qualidade Total pode não responder as necessidades específicas da enfermagem entretanto, julgamos que, os seus princípios e estratégias poderão ser utilizados em qualquer segmento que objetive atender as necessidades humanas.

\section{REFERENCIAL TEÓRICO}

Visando à consolidação da perspectiva da GQT, que já havia definido as metodologias para as ações de manutenção e melhoria da qualidade, foi criado o método Desdobramento da Função Qualidade (QFD), destinado ao desenvolvimento de produtos inicialmente implantado nas indústrias e hoje, já se faz presente em alguns segmentos voltados à prestação de serviços.

HALLBERG \& TIMPKA (1996) aplicaram este método em três projetos direcionados a instituições de saúde e constataram que o QFD pode ser usado no desenvolvimento de diferentes tipos de serviços. Entretanto, na enfermagem, nada se tem falado sobre ele.

Embasado nos conceitos da GQT, o método QFD operacionaliza o planejamento da qualidade através de desdobramentos e priorizações sucessivas das informações e atividades.

O QFD é definido por CHENG (1995b, p. 24) como sendo "uma forma de comunicar sistematicamente a informação relacionada com a qualidade e de explicitar ordenadamente o trabalho relacionado com a obtenção da qualidade". KANEKO (1994, p. 65) refere que "o desdobramento da qualidade é um processo para converter as necessidades de qualidade dos clientes a características técnicas e assim determinar a qualidade do projeto para o produto final".

ABREU (1997), ressalta o QFD como um método prático e eficaz que indica ao executivo o que fazer, para satisfazer o seu cliente, pois capacita a empresa "ouvir o que seus clientes dizem e rapidamente assimilar, sistematizar e transformar em produtos, serviços ou processos adequados os requisitos solicitados." (p. 49).

Quanto às etapas a serem efetuadas no planejamento, CHENG (1995a) apresenta oito. KANEKO (1994) e JURAN (1992) enunciam como sendo nove. O número de etapas varia pois estas dependem da especificidade de cada produto/serviço a ser desenvolvido.
No QFD os desdobramentos são operacionalizados através de ferramentas como tabelas, matrizes e modelos conceituais. Destes, abordaremos sobre os dois primeiros, visto terem sido utilizados no presente estudo.

A unidade básica de trabalho deste método é a tabela de desdobramento ou diagrama de árvore representada na forma triangular cujo significado busca detalhar algo (informação, atributo...) de forma ordenada e em níveis. O seu objetivo é permitir que o desconhecido se torne conhecido. O número de níveis não são pré estabelecidos. O importante é que no final os dados sejam emitidos da forma mais concreta e operacional possível.

Com relação à matriz, esta é constituída de duas tabelas e intenta dar visibilidade às relações entre os seus dados e assim direcionar a tomada de decisões. As relações podem ser qualitativas (extração); quantitativas (conversão) e de intensidade (correlação).

Percebendo esse sistema de gerenciamento como alternativa, para otimizar nossa prática, uma vez que propõe o estabelecimento de metas e processos coerentes ao contexto a ser desenvolvido conjugado à humanização e o trabalho, propusemo-nos a verificar se o método Desdobramento da Função Qualidade é passível de ser transportado para o serviço de enfermagem.

O objetivo deste estudo foi criar um modelo de Planejamento para o Serviço de Enfermagem adaptando-se as etapas e ações do método QFD.

\section{METODOLOGIA}

O tipo de estudo efetuado foi o exploratóriodescritivo e dentre a diversidade de amostras, utilizamos a aleatória simples e por conglomerados.

A primeira foi utilizada no sorteio dos hospitais que participaram da pesquisa e a segunda, consistiu na participação dos clientes lá presentes.

Para a definição dos locais da pesquisa, elaboramos a listagem dos hospitais de Ribeirão Preto, de acordo com a semelhança no número de leitos, especialidades médicas oferecidas e convênios. Em seguida, procedemos ao sorteio de três destas instituições. Entretanto, apenas duas fizeram parte da investigação visto que uma delas negou o nosso pedido para pesquisa.

A população de estudo constou de clientes hospitalizados em dois hospitais gerais de médio porte na cidade de Ribeirão Preto, residentes ou não neste município.

A coleta dos dados constituiu-se de duas fases com amostras distintas.

A primeira fase contou com uma amostra de 106 clientes hospitalizados, durante o mês de julho de 1996. 
Utilizando-se de um formulário contendo duas perguntas abertas (Anexo 2), foram entrevistados 53 clientes de cada um dos dois hospitais. Dessa forma, para completar este número, em uma das instituições, a pesquisa estendeu-se por mais uma semana. Esta fase consistiu no levantamento dos atributos de qualidade dos clientes e que, posteriormente, foram desdobrados para a obtenção das Qualidades Exigidas (QE).

A segunda fase, teve como finalidade quantificar e reconfirmar dados coletados e desdobrados junto a primeira amostra, contando com a participação de 8 clientes. O instrumento utilizado foi um formulário (Anexo 3) contendo 24 itens cujas respostas eram do tipo fechadas e consistiu da atribuição do grau de importância às QE.

Ressaltamos que o tamanho da segunda amostra não é representativa, quando se propõe tomar decisões para a consecução de empreendimentos de maior impacto, mas por se tratar ainda de um estudo preliminar, ou seja um modelo, julgamos estar de acordo.

Os respondentes foram homens e mulheres que possuíam idade entre 18 e 84 anos, orientados no tempo e espaço, com capacidade de verbalização, pós-cirúrgicos, com tempo mínimo de 72 horas de internação e alta prevista para as próximas 24 horas.

Quanto à execução da pesquisa, inicialmente, obtivemos a autorização formal dos hospitais para seleção da amostra e coleta dos dados.

Durante o período de coleta, visitamos as instituições nos turnos da manhã e/ou tarde e perguntamos ao enfermeiro do setor ou médico, quando estava presente, sobre as possíveis altas para as próximas 24 horas. A seguir, através das informações obtidas dos enfermeiros e do prontuário médico, era verificado se os dados do cliente preenchiam os requisitos que definiam a amostra.

No momento de coleta dos dados, o cliente era comunicado sobre a pesquisa, o seu propósito, técnica a ser utilizada, a garantia do anonimato e convidado a participar. Se a resposta fosse positiva, o cliente assinava a Autorização para Pesquisa em duas vias (Anexo 1) sendo uma via entregue para ele e a outra ficava com a pesquisadora. A seguir, procedíamos à coleta das informações através de uma única sessão na própria enfermaria ou em outro ambiente que lhe garantisse a privacidade. No final de cada coleta, para validação das informações, foi permitido ao cliente ler ou ouvir as suas respostas.

Os dados da segunda amostra foram coletados durante o último final de semana do mês de agosto de 1996 cujas características se enquadravam com os da primeira amostra.

Os participantes desta fase foram orientados a atribuir nota de 1 a 5 para cada Qualidade Exigida onde o menor escore seria atribuído ao(s) item(s) de pouca/ menor importância e o maior escore, aos item(s) de maior/ mais importância.

A apuração dos dados foi realizada manualmente e por computador e as informações apresentadas em forma de Quadros, Matrizes e Tabelas.

Como principal referencial teórico do método QFD, utilizamos os enunciados de CHENG (1995b) acrescido de KANEKO (1994) e JURAN(1992). Vale lembrar que essas abordagens são direcionadas à produção de bens de consumo ou a serviços comerciais mas nem por isso impossibilita a sua inserção no contexto da enfermagem. Ademais, consideramos que os riscos, as quedas e as "dores" fazem parte do desafio de se buscar novos conhecimentos e implementar mudanças.

\section{RESULTADOS E DISCUSSÃO}

No Quadro 1 apresentamos as etapas do planejamento da qualidade do serviço de enfermagem elaborado com base nos dados obtidos dos clientes e estabelecidas por meio do método Desdobramento da Função Qualidade (QFD).

\section{Quadro 1 - Etapas do planejamento da qualidade do serviço de enfermagem estabelecidas de acordo com o método QFD}

01 - Definir/delimitar os clientes;

02 - Identificar as necessidades dos clientes;

03 - Determinar as qualidades exigidas;

04 - Priorizar as necessidades dos clientes;

05 - Traduzir a "voz dos clientes" para a linguagem técrica de enfermage miestabelecimento das características do serviço de enfermagem;

06 - Estabelecer formas de avaliação das características de qualidade do serviço de enfermagem;

07 - Prionzar as características do serviço de enfermagem;

08 - Estabelecer "valores-padräo" para as características;

09 - Listar os procedimentos de enfermagem;

10 - Priorizar os procedimentos de enfermagem;

11 - Detalhariredefinir os procedimentos de enfermagem para atender as características estabelecidas;

12 - Documentar os procedimentos num "Manual Provisónio";

13 - Propor meios para treinar $\propto$ pessoas de acordo com o "Manual Provisónio";

14 - Executar o serviço de acordo com o "Manual Provisónio";

15 - Propor meios para acompanhar e avaliar o cumprimento e os resultados dos procedimentos;

16 - Revisar o "Manual Provisónio" e estabelecer o "Manual Definitivo" para o serviço de enfermagem;

17 - Refletir continuamente sobre os "procedimentos" executados no planejamento do serviço de enfermagem.

Etapa 1 - consiste em definir e delimitar os clientes e a amostra. Estas informações já foram enunciadas anteriormente no tópico destinado à metodologia. 
Etapa 2 - Identificação das necessidades dos clientes. Caracteriza-se pela coleta e início da organização dos dados. Esta fase permitiu coletar os dados originais ou necessidades referidas pelo cliente. Posteriormente, as seis necessidades com maior número de menções foram desdobradas. Os dados originais foram também categorizados por afinidade formando 20 grupos, como mostra a Tabela 1 .

Tabela 1 - Categorização dos dados originais mencionados pelos clientes e respectivas freqüências de citações

\begin{tabular}{|c|c|}
\hline CATEGORIASIDADOSORIGINAIS & FREQÜEANCIA \\
\hline $\begin{array}{l}\text { - ser educado - carinhoso, paciente, bondoso, } \\
\text { arnável, respeito, controle ernocional, agradável, } \\
\text { gentil, arnigo, calmo, compreensivo } \\
\text { - ter boa comunicação - atencioso, interessar-se, } \\
\text { ouvir, conversar, cornunicar, comparecer mais na } \\
\text { enfermania e perguntar } \\
\text { - atender rapidarnente quando charnar } \\
\text { - gos tar do que faz - dedicado, boa vontade, } \\
\text { presteza } \\
\text { - ter experiência prática } \\
\text { - ter conhecimento teónico } \\
\text { - ser cuidadoso - delicadeza } \\
\text { - ter bom humor - simpatia, descontração } \\
\text { - ter responsabilidade - saber o que faz, honesto, } \\
\text { não faltar ao serviço } \\
\text { - separar problemas pessoais do trabalho } \\
\text { - ter boa aparência - apresentação } \\
\text { - dar os medicamentos na hora certa } \\
\text { - deixar o cliente participar - escolher } \\
\text { - trabalhar em equipe - não falar mal dos colegas, } \\
\text { ajudar } \\
\text { - sejam saudáveis } \\
\text { - dar assistência religiosa } \\
\text { - não discriminar } \\
\text { - marter silêncio no setor } \\
\text { - falar menos } \\
\text { - ajudar o médico }\end{array}$ & $\begin{array}{l}25 \\
23 \\
21 \\
19 \\
17 \\
17 \\
11 \\
8 \\
5 \\
4 \\
4 \\
4 \\
\\
4 \\
2 \\
2 \\
2 \\
1 \\
1\end{array}$ \\
\hline TOTAL & 349 \\
\hline
\end{tabular}

Etapa 3 - Determinação das Qualidades Exigidas (QE) - As necessidades são referidas pelo cliente de forma genérica. Deste modo, nesta fase, os dados foram desdobrados através do diagrama de árvore, em níveis, para que representem as verdadeiras exigências dos clientes de forma resumida, sistemática e concreta como mostra o Quadro 2. As QE, situam-se na dimensão do "O QUE FAZER".

Quadro 2 - Exemplo de desdobramento dos dados originais em qualidades exigidas

\begin{tabular}{|l|l|l|}
\hline Nível primánio & Nível secundáno & \multicolumn{1}{c|}{ Nível terciánio } \\
\hline - ser educado & $\begin{array}{l}\text { - cortesia no } \\
\text { atendimento } \\
\text { - paciência às } \\
\text { solicitaçóes }\end{array}$ & $\begin{array}{l}\text { - responde imediatamente } \\
\text { - orienta nutas sobre a rotina } \\
\text { hospitalar } \\
\text { - fala compreensiva }\end{array}$ \\
\hline
\end{tabular}

Lembramos que nível secundário estão também presentes as exigências percebidas pela enfermagem. Este procedimento foi efetuado para os seis dados originais mais freqüentes, dos quais resultaram em $24 \mathrm{QE}$.

A etapa seguinte, a de número 4 , consiste na priorização das necessidades dos clientes. Este processo decorre do grande número de QE que são extraídas dos dados originais. Dessa forma, através da participação da segunda amostra foram atribuídas notas a cada item de QE (Tabela 2). A média aritmética resultante determinou quais eram mais importantes.

Tabela 2 - Demonstrativo do grau de importância atribuídos pelos clientes às qualidades exigidas

\begin{tabular}{|c|c|c|c|c|c|c|c|c|c|}
\hline CLIENTES & \multicolumn{8}{|c|}{ NOTAS } & \multirow{2}{*}{$\begin{array}{l}\text { MÉ } \\
\text { DIA }\end{array}$} \\
\hline $\begin{array}{l}\text { QUALDADH } \\
\text { EXIGIDAS }\end{array}$ & $\mathrm{A}$ & B & C & $\mathrm{D}$ & E & $\mathrm{F}$ & G & $\mathrm{H}$ & \\
\hline
\end{tabular}

Responde imediatamente 5,0 4,0 5,0 3,5 5,0 4,0 4,0 3,0 4,18 as perguntas

Orienta sobre a rotina $3,0 \quad 3,0 \quad 4,02,5 \quad 5,03,8 \quad 4,5 \quad 5,03,85$ hospitalar

Fala compreensiva $\quad 5,04,0 \quad 5,03,0 \quad 5,03,7 \quad 4,0 \quad 5,04,33$

Atende as solicitações $5,0 \quad 3,04,04,0 \quad 3,04,0 \quad 5,0 \quad 5,04,12$ rapidamente

Explica a razão da espera $3,0 \quad 4,0 \quad 3,0 \quad 1,5 \quad 5,0 \quad 3,9 \quad 4,0 \quad 4,03,55$

Prática no manuse io dos 4,0 5,0 4,0 2,5 5,0 4,5 5,0 5, 4, 47

materiais e equipamentos

Prática para fazer os $5,0 \quad 5,04,03,5 \quad 5,0 \quad 5,0 \quad 5,0 \quad 5,04,68$ cuidados

Mantém em posição $5,0 \quad 5,04,04,5 \quad 5,0 \quad 4,0 \quad 5,0 \quad 4,04,56$ confortável

Procura diminuir a dor $\quad 5,0 \quad 5,0 \quad 3,05,0 \quad 5,0 \quad 5,0 \quad 5,0 \quad 5,0 \quad 4,75$

Evita ferimentos $\quad 5,0 \quad 5,04,02,5 \quad 5,04,7 \quad 5,0 \quad 5,04,52$

Previne infecção $\quad 5,0 \quad 5,0 \quad 5,03,5 \quad 5,04,9 \quad 5,0 \quad 4,04,67$

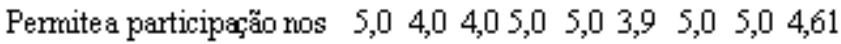
cuidados

Interessa-se em saber 4,0 5,0 5,0 5,0 5,0 4,8 4,0 5,0 4,72

corno está sendo cuidado

Dispõe-se a ajudar os $5,0 \quad 5,0 \quad 5,03,5 \quad 5,04,0 \quad 4,0 \quad 5,04,56$ outros

Continua os cuidados dos 4,0 4,0 4,5 4,5 $\quad 5,0 \quad 4,5 \quad 4,0 \quad 4,0 \quad 4,31$

plantões anteriores

Mantémo setor emordem $5,0 \quad 5,0 \quad 5,05,0 \quad 5,0 \quad 4,2 \quad 4,0 \quad 5,0 \quad 4,77$

Cumpre as nomas do $4,04,05,05,0 \quad 5,0 \quad 3,8 \quad 5,0 \quad 4,04,47$ hospital

Explica com jeito fácil de $5,0 \quad 5,0 \quad 5,04,5 \quad 5,0 \quad 4,3 \quad 5,0 \quad 5,0 \quad 4,85$ entender

Comunica-se com as $5,04,04,05,0 \quad 5,04,7 \quad 4,0 \quad 5,04,58$ pessoas certas

$\begin{array}{llllllllll}\text { Passa as informações sem } 4,0 & 5,0 & 5,0 & 5,0 & 5,0 & 4,0 & 5,0 & 4,0 & 4,62\end{array}$ demora

Faz os cuidados de acordo $5,0 \quad 5,0 \quad 5,0 \quad 5,0 \quad 5,0 \quad 3,9 \quad 4,0 \quad 5,0 \quad 4,73$ com a teoria

Explica sobre o que vai $4,0 \quad 4,0 \quad 3,05,0 \quad 5,0 \quad 4,0 \quad 5,0 \quad 5,0 \quad 4,37$ fazer

Rapidez para decidir $\quad 5,05,05,05,0 \quad 5,03,0 \quad 5,0 \quad 4,04,62$

Decide certo 
As seis QE com maior escore foram: dá explicações fáceis de entender, mantém o setor em ordem, procura diminuir a dor, cuida de acordo com a teoria, interessa-se em saber como está sendo cuidado e prática em efetuar os cuidados.

De acordo com essas QE, observamos que no atendimento de enfermagem, o cliente valoriza mais os aspectos interacionais do que os técnicos. Essa afirmação corrobora com SILVA (1994); KAMIYAMA (1972) e DONABEDIAN (1988) que também ponderam sobre esta ótica.

DRUMOND (1995, p. 80) refere que a análise dos dados priorizados é de vital importância para o trabalho de planejamento visto que: "fornece argumentos para avaliar se a melhor estratégia é criar um único produto ou segmentar o mercado...".

Etapa 5 - Estabelecimento das Características de Qualidade (CQ) do Serviço de Enfermagem. Esta fase consiste em converter a voz do cliente em características técnicas do serviço para avaliar se as necessidades dos clientes estão sendo atendidas. As características encontram-se na dimensão do "COMO FAZER" e devem ser expressadas em termos qualiquantitativos. Esse processo foi realizado através do desdobramento das seis QE priorizadas das quais foram extraídas $11 \mathrm{CQ}$, conforme observamos no Quadro 3.

Quadro 3 - Modelo de tabela utilizada para o estabelecimento das características de qualidade do serviço de enfermagem

\begin{tabular}{|l|l|}
\hline Qualidades Exigidas & Características de Qualidade \\
\hline - responde ime- & - tempo de e spera para ser \\
diatamente às & atendido \\
perguntas & - taxa de atendimento das \\
& solicitações dos clientes \\
& - quantidade de intercorrências \\
& - número de reclamações \\
& - taxa de clientes satisfeitos \\
\hline
\end{tabular}

A próxima, etapa a de número $\mathbf{6}$, consiste no Estabelecimento de Formas de Avaliação das Características de Qualidade (CQ) - Nesta fase, foram determinados os critérios, tipo de informações e os responsáveis pelo acompanhamento e controle das mesmas.
Quadro 4 - Exemplo de características de qualidade do serviço de enfermagem e formas de avaliação

\begin{tabular}{|l|c|}
\hline Características de Qualidade & Formas de Avaliação \\
\hline - tempo de espera & - tempo médio de espera \\
para ser atendido & entre a solicitação e o \\
- taxa de clientes & andamento pela equipe, \\
satisfeitos & observados pelo cliente e \\
& enfermeiro assistencial \\
& - percentual mensal de \\
& satisfação dos clientes, \\
& obtidos pelo enfermeiro \\
& assistencial, por ocasião \\
da alta hospitalar
\end{tabular}

A seguir, determinamos quais CQ atuam de forma mais significativa no serviço. Para tanto, efetuamos a priorização das mesmas como exposto na etapa 7.

Esta fase foi efetuada através da MATRIZ I (MATSUDA, 1997, p. 108) onde nas linhas, colocamos os itens de QE e nas colunas, as CQ. Parte dessa matriz será apresentada a seguir. Segundo OLIVEIRA \& BOAN (1995, p. 93), a matriz é a principal ferramenta para "coletar, processar e dispor os dados".

Efetuamos as correlações seguindo a pergunta básica: "a característica atende às necessidades do cliente?" considerando, individualmente, cada item de uma tabela, assinalamos no interior de cada célula com um dos símbolos a seguir apresentados.

Quadro 5-Símbolos e valores utilizados nos processos de correlação e conversão

\begin{tabular}{|l|c|c|}
\hline Correlação & Símbolo & Valor \\
\hline forte & $\subseteq$ & 9 \\
média & $c$ & 3 \\
fraca & 4 & 1 \\
inexistente & em branco & 0 \\
\hline
\end{tabular}

Fonte: CHENG, L.C. et al. QFD Planejamento da Qualidade, 1995. p. 105.

Terminadas as correlações, procedemos à conversão dos dados multiplicando o valor do símbolo pelo valor das $\mathrm{QE}$ e registramos no interior de cada célula. A seguir, somamos todos os valores de cada coluna e embaixo, na matriz, registramos como peso absoluto. Do 
somatório dos pesos absolutos foram obtidos pesos relativos, percentuais para cada característica, determinando assim, aquelas características mais importantes a saber: taxa de atendimento das solicitações, taxa de clientes satisfeitos, número de inquéritos por questões éticas, quantidade de intercorrências, tempo de espera para ser atendido e número de registros no prontuário sobre procedimentos efetuados.

MATRIZ I - Priorização das características de qualidade

\begin{tabular}{|c|c|c|c|c|}
\hline $\begin{array}{l}\text { Carac. de Qualidade do } \\
\text { Serviço de Enfermagem }\end{array}$ & $\begin{array}{l}\text { Tempo de } \\
\text { espera para } \\
\text { ser atendido }\end{array}$ & $\begin{array}{l}\text { Número de } \\
\text { inquéritos por } \\
\text { questóes éticas }\end{array}$ & $\begin{array}{c}\text { Taxa de } \\
\text { atendimento } \\
\text { das solicitaçóes }\end{array}$ & $\begin{array}{l}\text { Quantidade de } \\
\text { intercorrências }\end{array}$ \\
\hline Responde imediatamente às perguntas & C 37,62 & $\therefore 4,18$ & $\bigodot 37,62$ & $\Delta 4,18$ \\
\hline Orienta sobre a rotina hospitalar & & $\triangle 3,85$ & $\triangle 3,85$ & $\triangle 3,85$ \\
\hline Fala compreensiva & & c 12,99 & & $\Delta 4,33$ \\
\hline Atende às solicitações rapidamente & C 37,08 & $\odot 37,08$ & $\odot 37,08$ & $c 12,36$ \\
\hline
\end{tabular}

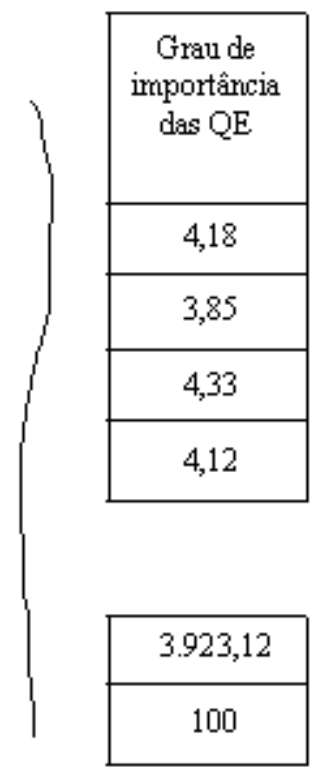

\begin{tabular}{|l|c|c|c|c|}
\hline Peso absoluto & 378,17 & 463,65 & 553,74 & 441,76 \\
\hline Peso relativo & 9,64 & 11,82 & 14,11 & 11,26 \\
\hline
\end{tabular}

que consiste na Listagem dos Procedimentos de

Etapa 8 - Estabelecimento dos "ValoresPadrão" para as CQ do serviço de enfermagem - são as metas para a melhoria/manutenção das características. Como exemplo citamos: para a característica taxa de atendimento de solicitações do cliente, estabelecemos o valor-padrão de $90 \%$ de atendimento por plantão.

Salientamos também que para a obtenção da qualidade, é preciso redefinir e padronizar os procedimentos. Dessa forma, passamos para a etapa 9

\section{Enfermagem.}

Devido ao número elevado, foram escolhidos apenas 18 procedimentos considerados como os mais elementares e executados pela maioria dos membros da equipe de enfermagem. É importante ressaltar que os critérios estabelecidos para a escolha dos procedimentos devem corresponder à realidade de cada clínica.

Quadro 6 - Lista de procedimentos de enfermagem considerados como os mais executados pela equipe de enfermagem

- Desenvolvimento de relação de ajuda;

- Manuseio correto de material esterilizado;

- Passagem de Plantão;

- Registro no gráfico;

- Verificação de SSWV;

- Imobilização no leito;

- Mudança de decúbito;

- Anotações de enfermagem;

- Punção venosa periférica;

- Preparo de medicamentos injetáveis;

-Sondagem nasogástrica;

- SVD;

- Aspiração de secreções de orofaringe e traquéia;

- Alimentação por sonda;

- Banho no leito;

- Curativo;

- Internação/admissão;

- Alta Hospitalar. 
Listados os procedimentos, efetuamos a etapa 10 objetivando a priorização das mesmas. Para isso, construímos a MATRIZ II (MATSUDA, 1997, p. 116) mantendo as CQ nas colunas e nas linhas, colocamos os procedimentos.

Efetuamos as correlações, conforme a MATRIZ I conduzindo-nos pela seguinte pergunta básica: "a característica avalia o procedimento?" Procedemos a conversão, multiplicando o peso relativo percentual de cada característica (obtido na MATRIZ I) pelo valor do símbolo atribuído a cada correlação e anotamos no interior de cada célula. A seguir, somamos todos os valores de uma linha e assinalamos no final da tabela ao lado direito.

Os seis procedimentos priorizados foram: $1^{\circ}$ ) desenvolvimento de relação de ajuda; $2^{\circ}$ ) passagem de plantão; $3^{\circ}$ ) anotações de enfermagem; $4^{\circ}$ ) verificação de Sinais Vitais; $5^{\circ}$ ) internação/admissão e $6^{\circ}$ ) aspiração de secreções da orofaringe e traquéia.

O passo seguinte, de número 11, consistiu no detalhamento e redefinição dos procedimentos priorizados. Estes foram efetuados de acordo com a literatura, a experiência profissional de enfermeiros assistenciais ou docentes, a realidade institucional, sobretudo, relacionados ao atendimento das necessidades do usuário.

A atividade desta etapa conduz à padronização dos procedimentos após terem sido transmitidos a todo o pessoal de nível operacional.

Cabe ressaltar que no momento da redefinição, devemos inserir as características de qualidade priorizadas bem como outras que forem pertinentes.

Etapa 12 - Documentar os Procedimentos num "Manual Provisório" - Após a redefinição dos procedimentos, cumpre documentá-los para que sirva de guia ao treinamento, implementação, avaliação e revisão, até se obter a padronização.

Etapa 13 - Propor Meios para Educar e Treinar as Pessoas de Acordo com o "Manual Provisório" - como estratégias sugerimos: palestras, grupos de discussão, oficinas de trabalho, aulas teóricopráticas em laboratório e atuação no local de trabalho, acompanhado pela chefia imediata que já deverá estar familiarizada aos novos procedimentos e métodos.

Etapa 14 - nesta fase, os procedimentos deverão ser efetuados de acordo com os passos propostos, a fim de detectar as anomalias e assim propiciar as ações corretivas.

Etapa 15 - Propor meios para Acompanhar e Avaliar o Cumprimento e os Resultados dos Procedimentos - segundo JURAN (1992), os dados deverão ser coletados sob as condições de trabalho, pois, é nesta fase que se detecta a maioria dos problemas. Para estas atividades, MATSUDA (1997, p. 136) elaborou dois formulários. Um para o enfermeiro que acompanha o treinando e outro, destinado ao cliente que avalia o procedimento recebido.

Etapa 16 - Revisar o "Manual Provisório" e Estabelecer o "Manual Definitivo" - Efetuadas as alterações, devemos preparar o "Manual Definitivo" e a padronização. Tais procedimentos porém, deverão ser monitorados/alterados, visto que as necessidades dos clientes mudam continuamente. Em unidades informatizadas, o uso deste sistema possibilita um meio rápido e fácil para as consultas.

Etapa 17 - Refletir Continuamente sobre os Procedimentos Executados no Planejamento do Serviço - Para sistematizar o processo de garantia da qualidade, é necessário o comprometimento de todos e a busca contínua da melhoria. Para tanto é necessário discutir e refletir sobre os processos e resultados junto as equipes intra e interprofissional bem como a busca de dados junto aos clientes e ex-clientes são de extrema importância.

\section{CONSIDERAÇÕES FINAIS}

Observando a trajetória administrativa da enfermagem, e considerando que a mesma deve estar inserida no contexto social que promove a saúde e o bemestar da população, percebemos ter havido avanços e retrocessos em decorrência das condições históricas de cada época. Hoje, ainda que sua prática "biologista" prevaleça em nosso meio, há indícios de que a categoria está percebendo a necessidade de se instituir mudanças.

Fazendo parte desse contexto, procuramos inserir um modelo de trabalho subsidiado em princípios que em nosso ver promove a parceria entre produtores/ trabalhadores e consumidores, com a conseqüente humanização, democratização e a otimização do serviço. Em que pese o tom romântico e ideológico que esta perspectiva nos apresenta, consideramos que os seus processos e resultados deverão ser vislumbrados pela enfermagem.

Em nosso entender, o QFD é uma opção a ser buscada, pois suas etapas são alicerçadas em objetivos e dados racionais, sem abandonar a intuição e a sensibilidade, que permitem visualizar todo o contexto a ser trabalhado.

Assentimos que, em razão de seu desconhecimento pela enfermagem, esse método necessita de mais estudos e adequações ligados tanto às ações propostas pela metodologia, quanto àquelas relacionadas à profissão visto que, ela possui especificidades de cunho ético-moral que jamais poderão ser esquecidas.

A construção deste estudo mostrou-nos que essa 
metodologia pode ser utilizada para o serviço de enfermagem, pois através dela é possível entender e atender o cliente naqueles aspectos que lhe são cruciais, facilitando assim o trabalho do enfermeiro no gerenciamento do serviço através do reconhecimento dos fatores que se traduzem em qualidade para o cliente, manutenção e uniformidade das ações desenvolvidas pela equipe, capacidade de previsão e provisão de recursos para suprir o atendimento. Ademais, em nosso entender, promove o inter-relacionamento com outros segmentos do hospital.

Concordamos diante deste primeiro estudo, com os estudiosos do QFD, que este método pode ser utilizado para desenvolver qualquer produto ou serviço.

\section{QUALITY FUNCTION DEPLOYMENT METHOD - QFD - IN THE PLANNING OF NURSING SERVICE}

"Focus on the client" is the posture that must be adopted in order to offer quality products. Based on the Total Quality Management approach, the Quality Function Deployment method (QFD) is a tool to achieve this goal. The purpose of this study is to create a proposal for planning the nursing services following the steps and actions of this methodology. The basic procedure was to survey the necessity of 106 hospitalized patients. Data were deployed using the seventeen steps proposed. Results showed that the interaction is more important than the technique according to the clients and also that this method enables the implementation of quality in nursing care.

\section{O MÉTODO DESDOBLAMIENTO DE LA FUNCIÓN CALIDAD - QFD - EN LA PLANEACIÓN DEL SERVICIO DE ENFERMERÍA}

"El cliente es lo primero" posición a ser adoptada en la obtención de productos de calidad. Estructurada en el abordaje de la Gestión por la Calidad Total, el Desdoblamiento de la Función Calidad, es la herramienta que operacionaliza esa perspectiva. Este estudio tuvo como objetivo crear una propuesta de planeación para el servicio de enfermería siguiendo etapas y acciones de esta metodología, que comenzó con el levantamiento de las necesidades de 106 clientes hospitalizados. A través de matrices y diagramas, los datos fueron organizados y priorizados siguiendo las 17 etapas propuestas. El resultado mostró que en la atención de enfermería, el cliente valoriza la interacción mas que la técnica y que este método posibilita la implementación de la calidad.

TÉRMINOS CLAVES: desdoblamiento, planeación, enfermería, calidad

ANEXO 1

Solicitação de Entrevista ao Cliente

Ribeirão Preto, de de 1996.

Prezado(a) Senhor(a):

Estamos procedendo a uma pesquisa para ouvir as expectativas dos clientes relacionadas ao atendimento de enfermagem. À partir de então, pretendemos desenvolver um serviço que vise atender as necessidades mencionadas.

Solicitamos a gentileza de participar deste estudo respondendo às perguntas que serão feitas e registradas pela pesquisadora. No final será permitido que o $\operatorname{Sr}(a)$ leia ou ouça as suas informações certificando-se de que as mesmas estão de acordo.

A sua colaboração será de grande importância e certamente resultará em benefícios a todos que aspiram a um melhor atendimento à sua saúde.

Muito Obrigada.

\section{ANEXO 2}

\section{Instrumento de Pesquisa - 1}

\section{I - Dados Pessoais:}

- Pré-nome: Sexo: Idade: Escol:_ Comp. ( ) Incomp. ( )

- Prof. Est.Civil Cas. ( ) Solt. ( )

Viúvo ( ) Outro ( )

- Categ. de internação: SUS ( ) Convênio ( ) Particular ( )

- Freq. de internação: Dias internado:

\section{II - Dados Específicos:}

1- Na sua opinião, como as pessoas que trabalham na enfermagem devem ser para que o $\operatorname{Sr}($ a) sinta-se satisfeito e bem atendido? Cite 5 maneiras/jeitos necessários.

2- $\mathrm{O}$ que ainda falta no atendimento de enfermagem para que o $\operatorname{Sr}(\mathrm{a})$ sinta-se plenamente satisfeito? 
ANEXO 3

\section{INSTRUMENTO DE PESQUISA 2}

\section{I - Dados Pessoais:}

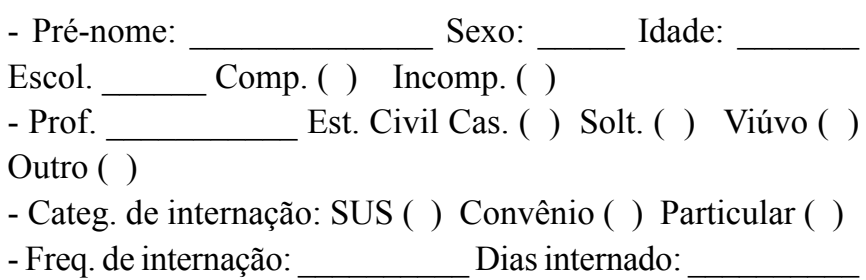

\section{II - Dados Específicos:}

1- Atribua qualquer nota de 1 a 5 para os itens que correspondem às Qualidades Exigidas para o atendimento de enfermagem. Lembramos que o valor 1 deve ser concedido para o(s) iten(s) de pouca importância e as notas acima desta, deverão ser atribuídas para os de maior importância. Os valores poderão ser repetidos sempre que o $\operatorname{Sr}(\mathrm{a})$ desejar.
QUALIDADES EXIGIDAS

Responde imediatamente às perguntas

Orienta sobre a rotina hospitalar

Fala compreensiva

Dá informações fáceis de entender

Comunica-se com as pessoas certas

Passa as informações sem demora

Atende as solicitações rapidamente

Explica a razão da espera

Permite a participação nos cuidados

Interessa-se em saber como está sendo cuidado

Dispõe-se a ajudar os colegas

Continua os cuidados dos plantões anteriores

Mantém o setor em ordem

Cumpre as normas do hospital

Prática no manuseio dos materiais e medicamentos

Prática para fazer os cuidados

Mantém em posição confortável

Procura diminuir a dor

Evita ferimentos

Previne infecção

Faz os cuidados de acordo com a teoria

Explica sobre o que vai fazer

Rapidez para decidir

Decide certo
NOTA

( )

( )

( )

( )

( )

( )

( )

( )

( )

( )

( )

( )

( )

\section{REFERÊNCIAS BIBLIOGRÁFICAS}

01. ABREU, F.S. QFD - Desdobramento da função qualidade estruturando a satisfação do cliente. Revista de Administração de Empresas - RAE, São Paulo, v. 37, n. 2, p. 47-55, abr/jun. 1997.

02. CAMPOS, V.F. TQC - Controle da qualidade total (no estilo japonês). 2. ed. Rio de Janeiro: Bloch, 1992.

03. CHENG, L.C. Planejamento da qualidade no TQC. In: CHENG, L.C. et al. QFD: planejamento da qualidade. Belo Horizonte: Líttera Maciel, 1995a. cap. 1, p. 3-17.

04. ․ Visão geral do desdobramento da função qualidade (QFD). In: CHENG et al. QFD: planejamento da qualidade. Belo Horizonte: Líttera Maciel, 1995b. cap. 2, p. 19-54.

05 . DONABEDIAN, A. The quality of care. How can it be assessed? JAMA, v. 260, n. 2, p. 23-30, Sept. 1988.

06. DRUMOND, F.B. Ouvindo o cliente para o planejamento do produto. In: CHENG, L.C. et. al. QFD: planejamento da qualidade. Belo Horizonte: Líttera Maciel, 1995. cap. 3, p. 5788.

07. HALLBERG, N.; TIMPKA, T. Experience from QFD techniques in service development. The eight symposium on quality function deployment. Sweden: Linköping University Press, 1996.

08. JURAN, J.M. Juran planejando para a qualidade. Trad. de João Mário Csillag e Cláudio Csillag. 2. ed. São Paulo: Pioneira, 1992.

09. KAMIYAMA, Y. O doente hospitalizado e sua percepção quanto à prioridade de seus problemas. Ribeirão Preto, 1972. 111 p. Tese (Doutorado) - Escola de Enfermagem, Universidade de São Paulo.

10. KANEKO, N. QFD (quality function deployment). Trad. de Manuel Matías Ojeda et al. Monterrey, México: Centro de Calidad, 1994.

11. MATSUDA, L.M. O método desdobramento da função qualidade - QFD - no planejamento do serviço de enfermagem. Ribeirão Preto, 1997. 206 p. Dissertação (Mestrado) - Escola de Enfermagem de Ribeirão Preto, Universidade de São Paulo.

12. OLIVEIRA, C.A.; BOAN, F.S. Tradução da voz dos clientes em informações de projeto. In: CHENG, L.C. et al. QFD: planejamento da qualidade. Belo Horizonte: Líttera Maciel, 1995. cap. 4, p. 91117.

13. SILVA, S.H. da. Controle da qualidade assistencial de enfermagem: implementação de um modelo. São Paulo, 1994. 243 p. Tese (Doutorado) - Escola de Enfermagem, Universidade São Paulo. 